\title{
CERTIFICAÇÃO DE CRÉDITO DE CARBONO NA SILVICULTURA DE ESPÉCIES EXÓTICAS E O PARADOXO DO POLUIDOR-CREDOR
}

Saulo de Oliviera Pinto Coelho

Vice-Diretor da Faculdade de Direito da Universidade Federal de Goiás - Brasil. Coordenador do Curso de Mestrado Profissional em Direito e Políticas Públicas da UFG. Professor do Programa de Pós-Graduação Interdisciplinar em Direitos Humanos da UFG. Email: saulopintocoelho@yahoo.com.br

Tiago Ducatti de Oliveira Silva

Mestrando em Direitos Humanos pela Universidade Federal de Goiás Email:tiagoducatti@hotmail.com

\section{RESUMO}

O presente trabalho se propõe a analisar a possibilidade de certificação das atividades de projeto florestais que empregam espécies exóticas e construir parâmetros para uma interpretação ecologicamente adequada para os possíveis conflitos que surjam entre as normativas nacionais e internacionais a esse respeito, bem como objetiva refletir criticamente, a partir dessa análise, sobre os aspectos paradoxais do modelo regulador atual, notadamente quanto à possibilidade de, em algumas situações, a silvicultura com espécies exóticas, ao mesmo tempo que possa ser considerada atividade poluidora ou potencialmente poluidora, possa ser igualmente credenciada como geradora de crédito de carbono, gerando um contrassenso na experiência jurídica brasileira. Adotou-se uma abordagem metodológica do direito como experiência, que, portando, busca superar a analise puramente abstrata do fenômeno jurídico. Recorreuse à realização de análises qualitativas de vertente teórico-dogmática. A partir de referenciais teóricos como os conceitos de constitucionalismo sustentável, ou de desenvolvimento sustentável constitucionalmente adequado; a perspectiva do desenvolvimento crítico-inclusivo e a crítica às patologias do desenvolvimento e do desenvolvimento mimético, buscou-se confrontar as diferentes perspectivas de interação dos padrões normativos internacionais com a regulação ambiental nacional, bem como os controles de constitucionalidade interespacial e de convencionalidade suscitáveis 
quanto ao tema, notadamente com foco na avaliação do (des)respeito aosprincípios constitucionais ambientais, nos modelos regulatórios empregados.

Palavras-chave: Política nacional de meio ambiente;Mecanismos de desenvolvimento limpo. Atividades de projeto florestal. Desenvolvimento sustentável.

\title{
CARBON CREDIT CERTIFICATION OF INVASIVE SPECIES SILVICULTURE PROJECTS AND THE POLLUTER-CREDITOR PARADOX
}

\begin{abstract}
This paper aims at whether or not it is possible to certificate forestry project activities, that employ exotic species, and aims at developing parameters for an environmentally friend interpretation that must be adopted for possible conflicts between national and international regulations, as well as critically thinking, through the analysis aforementioned, the paradox of today's regulatory model, since it's possible, in some situations, to be considered a source of pollution and, at the same time, generate carbon credits, what can be considered a nonsense, and needs to be treated by the juridical experience. In order to overcome a purely abstract analysis, this paper employs an methodological approach centered in the perception of law as an experience. This paper also employs the development of qualitative theoretical-dogmatic analysis. Adopting theoretical marks such as the sustainable constitutionalism, or the constitutionally correct sustainable development; the critical-inclusive development and the critic to development pathologies and mimetic development theory; this paper sought to confront the different perspectives on the international normative standards and the national environmental regulation, as well as the interspatial constitutional control and the constitutional conventionality control evocable due to the thematic, notably focusing on the (dis)respect to constitution's environmental principles evaluation of the regulatory standards employed.
\end{abstract}

Keywords: Environmental Policy. Clean development mechanism. Forestry project activitys. Sustainable development. 


\section{INTRODUÇÃO}

A preocupação internacional com as mudanças climáticas inspirou a produção de vários documentos e acordos internacionais, responsáveis por embasar essa área do Direito Ambiental.

Dentre os mencionados acordos, é imperativo destacar a Convenção-Quadro das Nações Unidas sobre Mudança do Clima, conhecida principalmente pela produção do Protocolo de Quioto, acordo que estabeleceu metas de redução de emissões de gás carbônico, com natureza cogente para os países desenvolvidos signatários da convenção.

Posteriormente, houve a regulação do mencionado protocolo pelo Acordo de Marraquexe, que previu os instrumentos para as reduções estipuladas nas metas do protocolo. Dentre as possíveis formas de redução de emissões, há a possibilidade de cadastrar projetos de florestamento e reflorestamento, utilizados a fim de retirar carbono da atmosfera.

Por outra parte, os silvicultores, produtores rurais e companhias que se dedicavam ao mercado, em expansão, de produção de madeira e insumos dela derivados por meio de projetos florestais monocultores (principalmente pinus e eucalipto), viram na possibilidade de certificação de carbono para seus empreendimentos uma oportunidade, tanto para majoração de resultados econômicos, quanto para a validação ambiental de suas atividades.

Frente a tal contexto, este trabalho busca responder as seguintes questões que o direcionam: É possível a constituição de sumidouros de carbono para a percepção de créditos no mercado regulado, valendose de florestas plantadas com espécies exóticas? Uma monocultora de pinus ou eucalipto pode ser considerada floresta para os propósitos dessa regulação? E, ainda que seja considerada um sumidouro de carborno, pode ser considerada um sumidouro legítimo para receber certificação de crédito por isso, em vista de outros problemas e riscos ambientais que esse tipo de monocultura gera? Como devem ser interpretadas as normativas relevantes a fim de se evitar o possível contrassenso representado pela possibilidade da configuração e um paradoxo frente à principiologia ambiental: a ocorrência provável de um poluidor-credor?

Isto posto, o presente trabalho se propõe a analisar a possibilidade de certificação das atividades de projeto florestais que empregam espécies exóticas e construir parâmetros para uma interpretação ecologicamente adequada para a questão. Deu-se especial atenção para os possíveis conflitos 
que surjam entre as normativas nacionais e internacionais a esse respeito, bem como para a interação dessas normativas com projetos florestam concretos existentes no Brasil que empregaram espécies exóticas e ainda assim receberam certificação de crédito de carbono.

Com isso, objetiva-se refletir criticamente sobre os aspectos paradoxais do modelo regulador atual, notadamente quanto à possibilidade de, em algumas situações, a silvicultura com espécies exóticas, ao mesmo tempo que possa ser considerada atividade poluidora ou potencialmente poluidora, possa ser igualmente credenciada como geradora de crédito de carbono (portanto atividade despoluidora), o que gera um contrassenso que precisa ser devidamente tratado na experiência jurídica brasileira.

Adotou-se uma abordagem metodológica referenciada na percepção do direito como experiência focado na tratativa dos modelos regulatórios no seu estado de efetivação concreta(Reale, 1999, 77-86), que, portando, busca superar a análise puramente abstrata do fenômeno jurídico. Recorreu-se, igualmente, à realização de análises qualitativas de vertente teórico-dogmática. A partir de referenciais teóricos como os conceitos de constitucionalismo sustentável, ou de desenvolvimento sustentável constitucionalmente adequado e de Estado de Direito democrático e ambiental (Canotilho, 2015, p. 23-32); e as perspectivas do do desenvolvimento crítico-inclusivo e da crítica às patologias do desenvolvimento e do desenvolvimento mimético (Pinto Coelho, 2014, p. 41-60), buscou-se confrontar as diferentes perspectivas de interação dos padrões normativos internacionais com a regulação ambiental nacional, bem como os controles de constitucionalidade interespacial (Barroso, 1998, p. 15-46) e convencionalidade (Mazzuoli, 2015) suscitáveis quanto ao tema, notadamente com foco na avaliação do (des)respeito aos princípios constitucionais ambientais, nos modelos regulatórios empregados, avaliados como indicamos, a partir dos casos concretos de certificação de crédito de carbono para silviculturas com espécies exóticas.

Essa testagem metodológica, como veremos, nos possibilitou alcançar, como principais resultados uma elaborada análise a respeito modelo brasileiro de regulação e aplicação dos Mecanismos de Desenvolvimento Limpo, bem como mapeamento das normativas internas, hipóteses e metodologias utilizadas para que seja possível certificar as atividades de projeto florestal no Brasil, além de uma consubstanciada crítica dos contrassensos e dificuldades de se validar a situação de certificação para silviculturas com espécies exóticas. 


\section{OS CRÉDITOS DE CARBONO E O MECANISMO DE DESENVOLVIMENTO LIMPO NO BRASIL}

\subsection{A configuração do modelo jurídico dos MDL}

A preocupação ambiental com as mudanças climáticas se expandiunas últimas décadas, principalmente em razão de problemas como a destruição da camada de ozônio e o aquecimento global.

Visando adotar medidas para combater tais condições prejudiciais, foram realizados eventos internacionais e firmados instrumentos jurídicos de igual alcance, com a intenção de regulamentar tais questões. Dentre os quais, destaca-se a Convenção-Quadro das Nações Unidas sobre Mudança do Clima, cujo objetivo reside em indicar as causas antrópicas de mudança do clima, e influenciá-las por meio de medidas diretas, como a redução de emissão de gases de efeito estufa, ou indiretas, como a conservação de sumidouros e reservatórios destes gases (MACHADO, 2007 apud CASARA, 2007).

Destaca-se que a convenção em estudo classificou as partes conforme seu desenvolvimento econômico, critério relacionado com a emissão de gases de efeito estufa, conforme deliberação da própria convenção, separando-as em partes Anexo I e das partes não-Anexo I. O Anexo I contém as partes que são países desenvolvidos, enquanto os países em desenvolvimento compõem as partes não-Anexo I.

Importante destacar que a convenção estudada é regulada por um órgão denominado Conferência das Partes (COP), prevista e regulada no artigo $7^{\circ}$ da Convenção do Clima, entendido como o órgão supremo da convenção, responsável, também, por tomar decisões que regulamentam as metas e institutos da referida convenção, além de buscar sua contínua implementação.

Dentre as diversas Conferências das Partes, destaca-se primariamente a COP 3, cujo principal produto foi o Protocolo de Quioto, documento que estabeleceu compromissos quantitativos da redução de emissões antrópicas, através da adoção de mecanismos, dentre os quais se destaca o mecanismo de desenvolvimento limpo - MDL, o único dos três mecanismos de flexibilização previstos que pode contar com a participação das partes não-Anexo I, ou seja, pelos países em desenvolvimento que ratificaram o protocolo.

O MDL consiste, basicamente, no desenvolvimento de 
atividades nos territórios das partes não-Anexo I, a fim de remover gases de efeito estufa ou reduzir suas emissões, com a finalidade de que estes passem a conhecer e dominar técnicas e procedimentos que promovam o desenvolvimento sustentável, ao mesmo tempo que auxiliam aos países do Anexo I cumpram suas metas de limitação de emissões (CALSING, 2005 apud CASARA, 2007).

Após o cumprimento de determinados requisitos e o devido trâmite junto aos órgãos instituídos pela COP 7, as reduçõesdas emissões de gases de efeito estufa, serão certificadas, gerando as denominadas de redução certificada de emissões - RCE's. Estas últimas, por sua vez, poderão ser negociadas no mercado global e adquiridas por países do Anexo I, para que possam completar a meta designada.

Para que um determinado projeto possa integrar o MDL, ele deverá cumprir certos requisitos de elegibilidade, contidos principalmente no Acordo de Marraquexe, em seu artigo 12, § 50, alíneas "a", "b" e "c", do Protocolo de Quioto, entendidos como a participação voluntária ou voluntariedade, os benefícios reais e mensuráveis de longo prazo à parte anfitriã, e a adicionalidade da atividade.

Sendo os primeiros de fácil acepção, é necessário discorrer sobre o requisito da adicionalidade, entendido como a exigência de que as reduções das emissões advenham diretamente da implantação da atividade de projeto, comprovando-se que tal redução não ocorreria sem a atividade de projeto. Para tanto, dois cenários são comparados, o de Business as Usual, indicando o desempenho histórico das atividades do mercado da região especificada (HANUM, 2007, p. 26),com o qual se estabelece uma referência das emissões de gases de efeito estufa registradas no período, denominada de linha de base (baseline), e o cenário que deverá ser analisado em sequência, após a instalação do projeto.

O principal documento para uma atividade de projeto é o documento de concepção de projeto, cuja elaboração compete aos participantes da atividade de projeto, que deverá conter descrição da atividade de projeto, de maneira detalhada, contendo título, participantes, tipo e características da atividade, as tecnologias empregadas bem como a maneira como se dará sua transferência, a localização, as estimativas e projeções de reduções das emissões (CASARA, 2007, p. 107; HANUM, 2007, p. 39).

De igual sorte, é necessário que o documento aponte a metodologia empregada para a linha de base, monitoramento e estimativa de redução de 
emissões, que deverá ser uma das previamente aprovadas pelo Conselho Executivo do MDL, ou uma nova metodologia que deverá passar pela aprovação do mesmo órgão (CASARA, 2007, p. 108; HANUM, 2007, p. 44).

Outro tópico de constância obrigatória no documento de concepção do projeto é o estudo de impacto ambiental, que deve abranger inclusive os possíveis impactos ambientais transfronteiriços, e, caso julgue necessário, a parte anfitriã poderá requisitar um relatório de impactos ambientais (CASARA, 2007, p. 109; HANUM, 2007, p. 48).

$\mathrm{O}$ apêndice $\mathrm{B}$ da referida decisão 17 da COP 7 estabelece, ainda, em seu item "e", que o estudo de impactos ambientais deverá ser realizado segundo os procedimentos exigidos pela parte anfitriã. $\mathrm{O}$ que implica dizer que quando o Brasil for parte anfitriã de uma atividade de projeto, o documento de concepção desta deverá apresentar o estudo de impactos ambientais e o relatório de impactos ambientais em conformidade com a Resolução $n^{\circ}$ 01/1986 do Conselho Nacional do Meio Ambiente, e demais normas existentes.

No que diz respeito às atividades de projeto de florestamento e reflorestamento no Brasil, o modelo de documento de concepção a ser seguido é o do anexo I da Resolução $n^{\circ} 02$ de 10 de agosto de 2005, da Comissão Interministerial de Mudança Climática (HANUM, 2007, p. 40). Entretanto, ressalta-se que o mencionado documento modelo em sua seção "F" se restringe a reescrever o item "e" da mencionada decisão da conferência das partes.

\subsection{As especificidades das atividades de projeto florestais como MDL}

Cumpre elucidar algumas questões relacionadas às especificidades que as atividades de projeto de florestamento e reflorestamento possuem, aplicando tudo o que foi previamente explanado sobre o mecanismo de desenvolvimento limpo.

Destaca-se inicialmente que a decisão 11 da COP 7 conceituou, em seu anexo 1, item 1, alíneas "b" e "c", florestamento (afforestation) e reflorestamento (reforestation), respectivamente, como:

a conversão, induzida diretamente pelo homem, de terra que não florestada por um período de pelo menos 50 anos, por meio do plantio, semeadura e/ou outra promoção 
induzida pelo homem de fontes naturais de semente (tradução livre). ${ }^{1}$

a conversão, induzida diretamente pelo homem, de terra não florestada em terra florestada por meio do plantio, semeadura ou outra promoção induzida pelo homem de fontes naturais de semente, em terra que já foi florestada, mas que foi convertida em terra não florestada (tradução livre). ${ }^{2}$

Necessário ressaltar que há, também, o conceito de floresta, de caráter eminentemente técnico, que afirma que florestas são as áreas de cobertura vegetal, natural ou exótica, com uma ou mais espécies, onde cerca de $10(\mathrm{dez})$ à $30 \%$ (trinta por cento) das árvores têm potencial de altura mínima entre dois e cinco metros na maturidade.

Com base nestes conceitos e no que foi apresentado sobre o mecanismo de desenvolvimento limpo, as atividades de projeto florestais somente poderão ser elegíveis para o mecanismo caso cumpram com os critérios de adicionalidade, desenvolvimento sustentável, e sejam advindos da indução humana. As áreas que naturalmente voltam a composição de floresta não podem ser consideradas para o projeto, posto que não são atividades de florestamento ou reflorestamento, além do mais, o mecanismo não prevê a conservação de florestas existentes como atividades de projeto válidas (RORIZ, 2010, p. 110).

Como afirmado acima, é necessário que o projeto contribua para o desenvolvimento sustentável para que seja elegível como atividade de projeto. Por este motivo, é necessário que, além da contribuição ambiental, o projeto seja capaz de desenvolver socialmente e economicamente a região do local em que está sendo implementado.

A fim de definir a adicionalidade do projeto para considerálo elegível, conforme afirmado anteriormente, é preciso levar em consideração as metodologias aplicáveis, bem como algumas ferramentas que comprovam o efetivo sequestro de carbono atmosférico.

Sobre as metodologias que podem ser utilizadas atualmente, o Conselho Executivo do Mecanismo de Desenvolvimento Limpo adota duas metodologias para as atividades de projetos florestais de larga escala (AR-AM0014 e AR-ACM0003), e duas metodologias para as atividades florestais de pequena escala (AR-AMS0003 e AR-AMS0007) (ONU,

\footnotetext{
1 The direct human-induced conversion of land that has not been forested for a period of at least 50 years to forested land through planting, seeding and/or the human-induced promotion of natural seed sources.

2 The direct human-induced conversion of non-forested land to forested land through planting, seeding and/or the human-induced promotion of natural seed sources, on land that was forested but that has been converted to non-forested land.
} 
2015, p. 261-266). ${ }^{3}$

A metodologia AM0014 trata sobre a atividade de projeto florestal em áreas de manguezais ou áreas alagadas, ${ }^{4}$ determinando a necessidade de se utilizar mais de $90 \%$ (noventa por cento) de espécies nativas da região previamente degradada.

A metodologia aprovada e consolidada ACM0003, por outro lado, visa a atender as demais atividades de projeto florestal, excetuandose as áreas de manguezais e alagadas, além da necessidade da área em questão não estar florestada.

As outras metodologias listadas para atividades de pequena escala reproduzem a sistemática de metodologia específica para áreas alagadas e manguezais, e uma metodologia para as demais áreas, apresentando requisitos específicos que as qualificam como de pequena escala.

Ademais, são utilizadas diversas técnicas para demonstrar que o projeto cumpre com a adicionalidade e remove gases de efeito estufa, dentre elas o mapeamento, através de geoprocessamento e sensoriamento remoto; o inventário da vegetação, determinado por técnicas de amostragem e mensuração de campo, utilizam-se, ainda, técnicas laboratoriais que determinam os teores de carbono, e a medição da biomassa dos vegetais do projeto (RORIZ, 2010, p. 115).

As técnicas baseadas em geotecnologia, são utilizadas para fixar o limite do projeto caracterizando, especificando o uso do solo e espécies vegetais, a fim de planejar a amostra que será estudada, localizandoa geograficamente pelo uso de imagens por satélite e fotografias aéreas (RORIZ, 2010, p. 116).

Ao inventariar a vegetação, é necessário que equipe técnica utilize de instrumentos de mensuração, com o objetivo de obter dados das unidades amostrais (RORIZ, 2010, p. 116).

A avaliação da biomassa, por sua vez, pode utilizar métodos indiretos, que utiliza o volume das árvores ou o peso de algumas amostras, ou métodos diretos, que promovem a mensuração de uma árvore média escolhida como amostra, ou utilizam uma série de secções da árvore em questão para o cálculo de sua biomassa (RORIZ, 2010, p. 117). Ao passo

3 Explicita-se que as siglas AM e ACM significam, respectivamente, que a metodologia foi aprovada (approved methodology) para aquele projeto na qual foi proposta, e que a metodologia é uma metodologia aprovada e consolidada (approved consolidated methodology) em razão de várias metodologias aprovadas para projetos similares. Além disto, a sigla AR remete à florestamento (afforestation) e à reflorestamento (reforestation), respectivamente, e a sigla AMS faz referência a metodologias aprovadas para pequena escala

4 Mangroove habitat (wetlands). 
que, os métodos laboratoriais utilizam-se de ácidos ou lasers que, ao entrar em contato com amostras secas das unidades de vegetação recolhidas, são capazes de gerar dados sobre os teores de carbono sequestrados RORIZ, 2010, p. 119).

Cumpridas estas especificidades referentes aos projetos de florestamento e reflorestamento, as atividades de projeto seguirão ordinariamente o rito de concepção, validação, aprovação, registro, monitoramento e emissão das reduções certificadas.

\subsection{Precisandoos termos daconflitividadenoflorestamentocom espécies exóticas: desenvolvimento sustentável como desenvolvimento multidimensional inclusivo e a insistência em não leva-lo a sério nas situações concretas}

As normas referentes ao mercado regulado de carbono prezam pelo desenvolvimento sustentável, estabelecendo-o como meta para a redução das emissões e retirada de gases de efeito estufa da atmosfera, delimitando, ademais, condições para que se considerem as áreas como elegíveis, bem como estabelecendo a realização de estudos de impactos ambientais conforme a legislação nacional, como já apontado. Mas é preciso levar a sério o conceito de desenvolvimento sustentável, para a tratativa concreta dos casos de proposição de MDL.

O conceito de desenvolvimento sustentável, que surgiu de maneira econômico-política com o Relatório Brundtland, possui reflexos jurídicos no ordenamento, sendo considerado como princípio de Direito Ambiental, conforme interpretação doutrinária do artigo $4^{\circ}$, inciso I, da Política Nacional do Meio Ambiente. Entretanto, em virtude do foco dado ao desenvolvimento ambientalmente sustentável, ou ao desenvolvimento economicamente sustentável, seu conceito no senso comum jurídico brasileiro é por vezes dotado de elevada "unidimensionalidade". Não se entende, muitas vezes, que essas dimensões são interdependentes.

A ideia de sustentabilidade é dotada de complexidade suficiente para ser compreendida de maneira "multidimensional", sendo somente assim que poderá guardar esse conceito coerência suficiente com o projeto constitucional posto em 1988, abarcando ao desenvolvimento ambiental, cultural, social e democrático (PINTO COELHO, 2012, p. 23). De forma semelhante, Canotilho afirma que é necessária "uma abordagem multifacetada e uma compreensão holística para captar a intrincada 
realidade subjacente e o subtil equilíbrio visado pela sustentabilidade" (2015, p. 79).

Canotilho elenca existência de uma dimensão procedimental do desenvolvimento sustentável, posto que ele deverá ser implementado para garantir o bem estar tanto da presente geração, quanto das gerações futuras. Tal processualidade depende efetivamente do princípio da participação, uma vez que as decisões que prezam pela sustentabilidade terão validade de acordo com a participação dos cidadãos atuais, garantindo, evidentemente, os interesses das gerações vindouras também (CANOTILHO, 2015, p. 81). Assim, complementando essa análise, a partir das observações de Pinto Coelho (2012, p. 25-26), podemos considerar que a sustentabilidade se constrói com a busca do complexo equilíbrio dos interesses dos diferentes setores da sociedade no seu presente, com os diferentes fins que a constituição estabelece para se perseguir nessa temática, somando-se aos diferentes cuidados que é preciso ter no presente, para com as projeções das escolhas no futuro.

Assim, como consequência, outra dimensão do desenvolvimento sustentável para Canotilho (2015, p. 81 et seq.) é a dimensão material, que, segundo o mesmo, comporta três vertentes, a vertente ambiental, a vertente social e a vertente econômica. A vertente ambiental deve ser entendida como a característica do desenvolvimento sustentável que se refere a forma correta de gerir os recursos naturais, respeitando a renovação dos recursos renováveis, e preservando os recursos não renováveis (CANOTILHO, 2015, p. 81).Quanto à vertente social, delimita-se que se refere à democrática e participativa distribuição dos ônus e bônus sociais, inclusive aqueles referentes às difíceis escolhas entre a produção econômica e a preservação do equilíbrio ambiental, determinando a participação do público, a fim de resguardar os indefesos de qualquer injustiça decorrente de impactos ambientais e da degradação de recursos naturais. Por fim, a vertente econômica do princípio do desenvolvimento sustentável determina que as atividades econômicas devem construir-se de modo estável e equilibrado, evitando as oscilações intensas entre crescimento e crise, tanto na macro, quanto na microeconomia, nisso incluindo-se a necessidade de pautar as atividades econômicas pelo uso de recursos renováveis, pela adoção das opções tecnológicas e logísticas menos poluidoras bem como, a redistribuição equitativa dos custos ambientais e sociais decorrentes das atividades promovidas, daí decorrendo importantes princípios, dentre eles aqueles relacionados à internalização das externalidades negativas, 
do qual deriva os princípios de direito ambiental brasileiro do "poluidorpagador" e do "usuário-pagador".

A quantidade de aspectos que estão enlaçados ao mencionado conceito variam de acordo com os autores, o último autor em destaque considerou existente três aspetos, ambiental, social e econômico. Há considerações que apresentam sete aspectos como essenciais ao desenvolvimento sustentável, como os aspectos social, econômico, ecológico, cultural, espacial, ambiental e político (PINTO COELHO, 2011, p. 265). Quanto aos citados aspectos, destaca-se a seguinte observação de Pinto Coelho (2011,p. 265: "se o desenvolvimento sustentável é um modelo de desenvolvimento, a sustentabilidade pode ser definida como um conceito relacionado à continuidade dos aspectos econômicos, políticos, sociais, culturais e ambientais da sociedade humana". Assim, a sustentabilidade deverá estar apoiada no tripé do desenvolvimento democrático ou político, social e ambiental, visando a redução das desigualdades, o fomento ao diálogo, a garantia de patamares mínimos da qualidade de vida, bem como a racionalização da relação do homem com os recursos naturais (PINTO COELHO, 2012, p. 23).

Por fim, resta a dimensão denominada por Canotilho de dimensão sincrônica. Esta dimensão do princípio em foco estabelece uma política regional na qual o desenvolvimento sustentável deverá ser apoiado em várias localidades, o que traduz a ideia de justiça espacial $(2015$, p. 81).

A mencionada dimensão deve ser entendida etimologicamente, como a dimensão "em que há sincronia" (FERREIRA, 1986), o que, consequentemente, deve ser compreendido como "ato ou efeito de manter uma operação em conjugação ou entrosamento com outra" (FERREIRA, 1986). Desta maneira, a dimensão sincrônica do desenvolvimento sustentável dita a propagação deste modelo de desenvolvimento abarcando espacialmente a maior área possível.

Desta feita, percebe-se o possível contrassenso, na possibilidade de, ao mesmo tempo, haver reduções certificadas de emissões em projetos que empregam a silvicultura exótica, tendo em vista a potencialidade poluidora dessa atividade em alguns casos.É inadmissível que as normativas do MDL permitam a poluição e a degradação ambiental nos países em desenvolvimento, a fim de gerar créditos de carbono e a consequente redução da poluição atmosférica. Uma vez que tal permissão é contrária ao desenvolvimento sustentável em suas dimensões sincrônica, posto que não haveria efetivação do modelo sustentável no país anfitrião; 
diacrônica, considerando que a degradação ambiental em questão seria responsável por prejudicar as futuras gerações; procedimental, levando-se em conta que não estaria sendo instaurado o desenvolvimento sustentável a fim de assegurar a justiça intergeracional; e, de igual maneira, haveria estrito descumprimento à dimensão material em seus aspectos ambiental e social.

Além do exposto quanto ao desenvolvimento sustentável, princípio norteador de ambas normativas, importante destacar que o Acordo de Marraquexe, no documento da Conferência das Partes de número sete, COP 7, determinou em seu item 27, alínea "c", que a Entidade Operacional Designada se encontra obrigada a cumprir as leis da Parte anfitriã quando promover a validação ou verificação e certificação das atividades de projeto propostas.

Assim, em uma das primeiras fases do ciclo de projeto da atividade do MDL, exige-se que a atividade, além de apresentar todos os requisitos de elegibilidade exigidos, quais sejam, adicionalidade, voluntariedade e apresentar benefícios à Parte anfitriã, também deverá estar em conformidade com a legislação de onde está sendo implementada.

Logo, em razão dos fundamentos axiológicos destacados, e da imposição de respeito à legislação nacional da Parte anfitriã, não se alcançaria, de um ponto de vista teórico enfocado nas normativas, o paradoxo do poluidor-credor, pois não haveria possibilidade, conforme as normativas internacionais de mudanças climáticas e mercado regulado de carbono, e as normativas nacionais que tratam sobre a poluição biológica, de se configurar o contrassenso permissivo ao paradoxo do poluidor-credor. Entretanto, em uma análise concreta das atividades de projeto que foram certificadas no Brasil, veremos que foi possível se constatar o contrário, revelando que o modelo jurídico constituído e a experiência efetiva destoam da interpretação adequada nas normativas e princípio em jogo.

Como já apresentado por este trabalho, o direito ao meio ambiente equilibrado e à sadia qualidade de vida é um direito fundamental, estabelecido constitucionalmente conforme dicção do artigo 225 da CF/1988. No entanto, é conhecida a distinção entre direitos fundamentais, aqueles direitos que foram reconhecidos e positivados na esfera constitucional de um estado, de forma a gerar um sistema de proteção interna, e direitos humanos, que se encontram consolidados em tratados de direito internacional, buscando estabelecer uma proteção ao ser humano, sem a necessária vinculação a um Estado, dotando-se, portanto, de caráter 
supranacional no âmbito do Direito Internacional dos Direitos Humanos 5 . Assim sendo, podemos considerar que o direito ao meio ambiente saudável e equilibrado é um direito humano-fundamental, que compõe tanto o bloco fundamental de constitucionalidade da $\mathrm{CRFB} / 88$, quanto o rol de direitos econômicos, sociais e culturais (DESC) reconhecidos pela ordem internacional.

Cabe, então, lembrar o entendimento já consolidado no estado da arte desse debate, no sentido de que odireito ao meio ambiente se constituiu como um direito humano-fundamental de terceira geração, posto que estes se encontram ancorados na fraternidade e solidariedade, e comumente possuem uma dimensão difusa, ainda que possa e deva produzir, nas situações concretas, imputações de direitos e deveres individualizadas ${ }^{6}$.

Desta feita, no caso de um possível conflito entre as normativas internacionais que dispõe sobre mudanças climáticas, e as normativas internas que impedem a poluição biológica (conflito somente possível de ser constatado no caso concreto, quando as características específicas de um projeto de florestamento ou reflorestamento assim o configurar, notadamente nas situações de uso de espécies exóticas ou nas situações de florestamentos tendencialmente monocultores), deverá ser aplicada a configuração normativa mais favorável (com mais peso à norma interna, ou à norma internacional, a depender de qual, em prevalecendo, produz maior nível de proteção no caso), mas sempre sem excluir com completo a outra, pois ambas, nessa situação, cumprem diferentes, mas igualmente importantes, funções complementares de promoção da sustentabilidade.

Pode-se aplicar como referência o entendimento de Canotilho, quanto ao princípio do nível elevado de proteção ecológica, princípio que rege as relações entre os membros da União Europeia, com a intenção de aproximar as legislações dentro da mencionada comunidade, a fim de estabelecer a impossibilidade de redução da proteção comunitária, gerando um denominador comum que deverá ser respeitado pelos países da comunidade. ${ }^{7}$ Como expõe o autor, o princípio do nível elevado da proteção ecológica determina a preterição da norma de direito interno ou comunitário que determine uma menor proteção ao meio ambiente. Desta

5 SARLET, 2007 apud MACHADO, Diego Pereira, Direitos humanos. 3 ed. Salvador, Bahia: Editora Juspodivm. 2015.

6 MACHADO, 2005 apud MIALHE, Jorge Luís, Direito Ambiental como expressão dos Direitos Humanos: a relevância do direito à informação no Mercosul. Verba Juris, ano 5, n. 5, jan/dez. 2006. p. 212.

7 CANOTILHO, op. cit. p. 47. 
maneira, caso a norma portuguesa estabeleça maior proteção ao meio ambiente que a norma comunitária, deverá ser cumprida a portuguesa, em razão de estabelecer um nível mais elevado de proteção. De igual maneira, caso a norma interna tenha menor nível protecionista, esta deverá ceder lugar, favorecendo-se a norma comunitária ou internacional.

No direito brasileiro também se estabeleceu o princípio da prevalência da norma ambiental mais protetiva, como decorrência e aprimoramento (no campo do Direito ambiental) do princípio da subsidiariedade em nosso federalismo complexo.

Assim, podemos concluir que o mandamento constitucional de realização racional da interação humana com o ambiente, de modo a garantir seu equilibrado devenir, capaz de permitir um desenvolvimento inclusivo e multidirecional, nos exige, ao mesmo tempo, ponderar a análise puramente ambiental das questões trazidas, com análises também de ordem econômica e social. Porém, não significa isso, sair do oito (um ambientalismo estrito), para adentrar num oitenta (um desenvolvimentismo econômico estrito). O desenvolvimento social, aqui, é o fiel da balança. Assim, impõese à análise um cuidado em evitar os reducionismos ambientalista ou desenvolvimentista, para pensar na normatividade vigente na sua relação com uma concepção de desenvolvimento que seja complexa, includente e não-reducionista, bem como (e sobretudo), crítica (cf. PINTO COELHO, 2014, p.46-48).

\section{CASUÍSTICA DAS ATIVIDADES DE PROJETO FLORESTAIS BRASILEIROS UTILIZADORES DE ESPÉCIE EXÓTICA QUE RECEBERAM DEFERIMENTO DE CERTIFICAÇÃO}

\subsection{Os três cases de reflorestamento certificados no Brasil}

Este tópico se dedica a analisar as atividades de projetos florestais aprovadas no Brasil, disponíveis no site do Ministério da Ciência e Tecnologia ${ }^{8}$, especificamente o "Projeto de Reflorestamento como Fonte Renovável de Suprimento de Madeira para Uso Industrial no Brasil" de 2008, o "Projeto MDL de Reflorestamento no Estado de São Paulo da AES Tietê" de 2010, e o "Projeto Vale Florestar - Reflorestamento de áreas tropicais degradadas na Amazônia Brasileira" de 2012.

Inicialmente, cumpre destacar que os projetos de 2008 e 2012 8 Disponível em: < http://www.mct.gov.br/index.php/content/view/57967/57967.html>. Acessado em: 28 de junho de 2016. 
tem como objetivo o reflorestamento.

No caso do projeto "Vale Florestar", o reflorestamento proposto é de pouco mais de 7.000 (sete mil) hectares com planta do gênero eucayptus, na parte degradada da Amazônia brasileira.

O projeto "Reflorestamento como Fonte Renovável de Suprimento de Madeira para Uso Industrial no Brasil" se limitou, em um primeiro momento, a afirmar na descrição do projeto que seria feito plantio para biomassa renovável, no entanto, em seu item “A.5.3" listou como espécies selecionadas para a atividade três espécies de eucalipto, visando à maior produtividade do projeto.

Das três certificações de crédito de carbono concedidas no Brasil a categoria "florestamente e reflorestamento" (existem outras categorias), apenas o projeto da "AES Tietê" de 2010, empregou espécies nativas. $\mathrm{Na}$ descrição da atividade foi empregado o termo reflorestamento, e, em suas páginas 4 e 5 foi afirmado que a proponente já realizou testes em área de pouco mais de 1.500 (mil e quinhentos) hectares plantando espécies nativas que não demonstram regeneração espontânea, abrangendo entre 80 (oitenta) e 126 (cento e vinte e seis) espécies nativas diferentes.

Quanto à avaliação da elegibilidade da terra para a atividade de projeto do MDL, os projetos seguiram o Anexo 18 da Reunião $\mathrm{n}^{\circ} 35$ do Conselho Executivo, realizada em Bonn, que dispõe sobre os procedimentos para a demonstrar que a área é elegível para projetos de florestamento e reflorestamento.

Seguindo o disposto no anexo, é necessário que se comprove que a vegetação está abaixo dos níveis definidos para que a área seja considerada como floresta, além de demonstrar que não há expectativa para que a vegetação local alcance os padrões mínimos para ser considerada dessa maneira.Além disto, é necessário, para osprojetos de florestamento, provar que há pelo menos 50 (cinquenta) anos a área em questão não é floresta, e, para os projetos de reflorestamento, é necessário que se comprove que a área não é floresta desde 31 de dezembro de 1989.

$\mathrm{O}$ anexo em questão elenca três meios capazes de atenderàs exigências estipuladas, o primeiro é o uso de imagens de satélite e fotos aéreas conjuntamente com dados referentes ao solo, assim como as informações do uso e cobertura do solo advinda de mapas ou conjunto de dados digitais referentes ao espaço, e, por fim, pesquisas baseadas no solo local, advinda de registros locais.

Durante a descrição do projeto, os documentos de concepção 
analisaram separadamente a elegibilidade da terra para as atividades propostas. O projeto "Vale Florestar - Reflorestamento de áreas tropicais degradadas na Amazônia Brasileira" apresentou avaliação de elegibilidade da terra, afirmando que a área não era floresta a partir da data estipulada do ano de 1989, utilizaram, ainda, de imagens de satélite, sistema de posicionamento global, além de fotografias aéreas, para elaborar mapas que demonstram as áreas elegíveis, definindo assim os limites do projeto.

O projeto "AES Tietê", de igual forma, utilizou-se das imagens de satélite, comparando imagens de 1989-1990 com imagens de 20062007, a fim de demonstrar que, desde a data inicialmente referida, a área não foi floresta.

O projeto "Reflorestamento como Fonte Renovável de Suprimento de Madeira para Uso Industrial no Brasil", utilizou-se, também, de imagens de satélite, para descrever a vegetação existente nos anos de 1989 e 2000. Interessante ressaltar que o documento de concepção deste projeto faz uma crítica à metodologia estabelecida no anexo 18 da reunião $\mathrm{n}^{\circ} 35$ do Conselho Executivo, afirmando que, antes da data limite estipulada, a terra era utilizada para plantação de florestas com vegetação não espontânea, o que impede que as mesmas integrem os limites do projeto, posto que inelegíveis, e que tal estava previsto antes da consolidação do mecanismo de desenvolvimento limpo.

Sobre a tecnologia empregada, os projetos diferem pouco, destacando principalmente o desenvolvimento de pesquisa e métodos de otimização dos processos de plantio, colheita e manejo, ${ }^{9}$ e, excetuando-se o projeto "AES Tietê", os demais listam ainda a otimização da gestão da qualidade, como tecnologia a ser empregada.

Quanto à transferência de tecnologia, o projeto "AES Tietê" afirma que o processo de transferência ocorrerá com literaturas e técnicas científicas por intermédio da ESALQ/USP. Quanto à transferência de tecnologia proposta pelo documento de concepção do projeto "Reflorestamento como Fonte Renovável de Suprimento de Madeira para Uso Industrial no Brasil", o mesmo afirma que não foi necessária a transferência de tecnologia de outros países, mas que o projeto pode resultar na mesma, o projeto "Vale Florestar - Reflorestamento de áreas tropicais degradadas na Amazônia Brasileira" afirmou o mesmo.

9 Contido nos Documentos de Concepção de Projetos, páginas 15 a 17 do "Reflorestamento como Fonte Renovável de Suprimento de Madeira para Uso Industrial no Brasil", páginas 12 a 14 do "Projeto MDL de Reflorestamento no Estado de São Paulo da AES Tietê", e, páginas 15 a 20 do "Projeto Vale Florestar - Reflorestamento de áreas tropicais degradadas na Amazônia Brasileira". 
No tocante às metodologias adotadas por cada projeto, destacase que o projeto "AES Tietê" adotou a metodologia AR-AM0010, o projeto "Vale Florestar - Reflorestamento de áreas tropicais degradadas na Amazônia Brasileira" adotou a metodologia AR-ACM0001, e, por fim, o projeto "Reflorestamento como Fonte Renovável de Suprimento de Madeira para Uso Industrial no Brasil" adotou a metodologia AR-AM0005.

As metodologias AR-AM0005 e AR-AM0010 foram aprovadas especificamente para os projetos brasileiros em estudo, sendo devidas para os casos de florestamento ou reflorestamento, em áreas de pastagens, como fonte de fornecimento de madeira para indústria e/ou usos comerciais; e florestamento ou reflorestamento implementados em áreas de pastos subutilizados em reservas ou áreas protegidas, respectivamente.

A metodologia consolidada AR-ACM0001 é embasada nas metodologias aprovadas AM-0003, AM-0006 e AM0032, sendo aplicável para os casos em que se promove o florestamento ou reflorestamento em áreas degradadas ou que continuariam degradas na ausência do projeto.

Exploradas as questões atinentes às metodologias, à tecnologia empregada e sua transferência para o país anfitrião, e às descrições feitas das atividades propostas e aprovadas, cabe agora investigar os estudos de impactos ambientais apresentados nos documentos de concepção de projetos.

O projeto "Vale Florestar - Reflorestamento de áreas tropicais degradadas na Amazônia Brasileira" inicia o tópico presente em seu documento de concepção de projeto, afirmando que o Conselho Estadual do Meio Ambiente do Estado do Pará não exige um estudo de impactos ambientais para as atividades de florestas plantadas, em razão das iniciativas negativas de desmatamento presentes na realidade da área em questão. Não obstante, o documento elenca nove possíveis impactos, dentre os quais estão listados como negativos apenas os referentes à introdução de espécies exóticas e à implantação da monocultura destas.

Dá-se prosseguimento ao estudo de impactos ambientais enumerando os benefícios que a espécie a ser introduzida, o Eucalyptus Urograndis, trará ao solo, ao desenvolvimento econômico, à paisagem, aos recursos hídricos, e ao ambiente local, posto que a área a ser utilizada é degradada e constitui área de pastagem. Por fim, o documento de concepção afirma que nenhum impacto negativo foi verificado, e que a atividade manterá monitoramento para os impactos ambientais.

Quanto ao projeto "Reflorestamento como Fonte Renovável 
de Suprimento de Madeira para Uso Industrial no Brasil", o documento de concepção do projeto alega que muitos dos argumentos contrários às plantações de eucalipto baseiam-se em "(...) mitos e preconceito", ${ }^{10}$ destacando que há argumentos que estão amparados em dados.

$\mathrm{O}$ documento prossegue colacionando dados e pesquisas que vão de encontro às alegações comumente proferidas sobre as florestas plantadas, tais pesquisas comprovam, por exemplo, que as árvores do gênero utilizadas não necessitam de mais água do que outras atividades empregadas. O documento, assim como o documento de concepção do projeto "Vale Florestar", apresenta também diversos argumentos sobre como a plantação contribui para o escoamento superficial, para a qualidade do solo, posto que gera serapilheira na área plantada, para a correção da acidez do solo, dentre diversos outros fatores.

Por outro lado, o estudo considera que apenas um impacto deve ser compreendido como de alta importância, entretanto, em atendimento ao princípio da precaução, decidiu considerar outro possível impacto como de alta relevância. Desta maneira, foram considerados dois impactos, quais sejam, o aumento da concentração de sólidos em suspensão, nutrientes e matéria orgânica nos cursos d'água; e, as mudanças no regime pluvial e na qualidade da água da bacia.

Afirma o documento que o primeiro impacto negativo não foi constatado no estudo, no entanto, alega que pode ser causado pela atividade de reflorestamento, motivo pelo qual será monitorado pelo projeto. Quanto ao segundo impacto, alega-se que não há elemento técnico que pode imediatamente avaliar tal situação, e que é controverso na doutrina, entretanto, o projeto se propõe a monitorá-lo.

Alega-se, ainda, que práticas de silvicultura que efetivamente resultam em uma menor taxa de erosão devem ser adotadas, e que práticas de conservação do solo e da água também devem ser adotadas, a fim de minimizar a possibilidade de danos a serem causados pelo projeto.

Por fim, destaca-se que o documento de concepção do projeto "AES Tietê" se limitou a descrever as vantagens da atividade no concernente à biodiversidade e ao sequestro de carbono, delimitando que a atividade não apresenta nenhum possível impacto negativo. Considerando que a mencionada atividade efetuará o reflorestamento com espécies nativas, não se percebe a existência de crítica cabível frente ao disposto no estudo de

10 Documento de concepção de projeto, p. 123. Disponível em: <http://www.mct.gov.br/upd blob/0200/200628.pdf>. Acessado em: 11 de maio de 2016. 
impacto ambiental como apresentado.

Por intermédio do estudo elaborado dos três casos acima analisados, percebe-se que o projeto "MDL de Reflorestamento no Estado de São Paulo da AES Tietê" se distingue dos demais analisados, em razão do uso de espécies nativas para o plantio, visando principalmente a recuperação das áreas degradadas e a preservação das áreas ciliares, motivo pelo qual é passível de classificação como um projeto conservacionista.

Por outro lado, os demais projetos apresentam caráter mais comercialista, considerando-se classificação simplificada, empregando monoculturas de eucalipto (dissimuladas pelo emprego de três diferentes espécies) e explorando a produtividade das mesmas. Entretanto, tais atividades não perderam, para a autoridade nacional designada para a certificação no Brasil, a adicionalidade típica de projetos do MDL, além de se firmarem, segundo esta autoridade, em terras elegíveis, em consonância com o disposto no Anexo 18 da reunião $\mathrm{n}^{\circ} 35$ do Conselho Executivo, e auxiliarem, na visão desse órgão, ambientalmente na recuperação das áreas degradadas. Ademais, para a autoridade designada estes dois projetos "não apresentam riscos de impactos ambientais que não possam ser monitorados, e para os quais cabem medidas preventivas e mitigadoras".

\subsection{As dificuldadesda certificação de sumidouros de carbono constituídos com espécies exóticas}

Refletindo-se criticamente sobre a posição da autorizada certificadora, é preciso considerar que aqui há um claro contrassenso, pois fica patente que a autoridade, ainda que implicitamente, reconhece que as monoculturas de eucalipto são potencialmente poluidoras (se não fossem, porque receberiam monitoramento ambiental e a atribuição de medidas mitigadoras?), mas ainda assim receberam uma certificação de crédito ambiental. Aí reside paradoxo que motiva esta investigação.

A aprovação destes projetos pode ser questionada de diferentes perspectivas. Uma delas é quanto ao próprio enquadramento como "floresta", ou "silvicultura". Todos os conceitos baseados no marco legal existente indicam uma monocultura (ainda que composta por três espécies da mesma família de vegetação arbórea) nunca se configura como floresta. Outro questionamento, caminha na direção da crítica aos benefícios de tais monoculturas apontados nos Estudos de impacto ambiental, pois obviamente, o fato que trazer algum benefício (claramente 
supervalorizados nos EIA analisados) não elide o caráter poluidor de uma atividade. Uma mineração traz benefícios, mas continua sendo atividade poluidora, portanto nunca poderia receber certificação de crédito de carbono. Sendo assim, também monoculturas de eucalipto não poderiam receber essa certificação. Um terceiro caminho, passa por entender que a estratégia para o estudo de impacto de plantações de eucalipto visando a certificação, se baseia principalmente na apresentação do caráter altamente degradado da área a se instalar a monocultura (normalmente áreas de pastagem) e na tentativa de afirmar e demonstrar que a silvicultura do eucalipto apresentaria uma melhoria nas condições da área, mesmo sendo uma atividade potencialmente poluidora. Ora, ainda que se admita que o florestamento de eucalipto seja menos degradante do ambiente que as pastagens anteriores (questão altamente controversa), certo é que isso não elide a pergunta se uma atividade degradante, pelo simples fato de ser menos degradante que a anterior, mereceria, nesse caso, a certificação como mecanismo de desenvolvimento limpo gerador de crédito de carbono. Essa, por evidente, somente pode ser respondida frente a casos concretos, mas o indicativo principal para orientar a resposta deve ser o de evitar o paradoxo tratado neste artigo, da figura do "poluidor-credor".

Com todo o exposto, levando-se em conta que o objetivo do mecanismo deverá ser alcançado mediante a adoção de medidas que assegurem o desenvolvimento sustentável, pode-se aduzir o uso de espécies exóticas por si só não impede a constituição de sumidouros de carbono certificáveis para percepção de créditos de carbono, porém, na análise do caso concreto deveria ficar patente o atendimento a todas as demais normas e princípios de direito ambiental. Ocorre que o florestamento por eucalipto, por suas características, dificilmente fugiria da configuração como atividade poluidora, segundo as classificações e caracterizações existentes nas normativas legais e do CONAMA. Assim, permanece para o caso do eucalipto o contrassenso da figura com poluidor-credor, caso recebam certificação de crédito de carbono. Não se quer dizer, com isso, que não se deva autorizar e licenciar ambientalmente o plantio de eucalipto. Mas que se deve licencia-lo como atividade poluidora, coisa bem diferente de certifica-lo como ambientalmente credora. 


\section{CONCLUSÕES}

Da avaliação dos problemas apresentados na introdução e da testagem das hipóteses realizadas no desenvolvimento deste trabalho, podemos sistematizar as seguintes considerações conclusiva:

1) A regulação internacional dos Mecanismos de Desenvolvimento Limpo e sua internalização no sistema brasileiro possui, em abstrato, uma adequação constitucional suficiente, com o modelo ambiental previsto da CRFB/88;

2) Porém, a avaliação dos (des)encontros dessa normativa com as demais normativas ambientais, na experiência jurídica brasileira, revela a possibilidade de situações concretas conflitivas e paradoxais, notadamente quanto à hipótese de certificação de créditos de carbono para silviculturas tendencialmente monocultoras e/ou realizadas com o plantio prioritário de espécies exóticas.

3) $\mathrm{O}$ entendimento constitucionalmente adequado do conceito de desenvolvimento sustentável, revela em seu caráter multifacetado, multidimensional, complexo e inclusivo, um referente para a correta tratativa em concreto de tais situações, porém é preciso levalo a sério quando da realização da jurisdição ambiental, seja ela em sede administrativa ou judicial.

4) $\mathrm{Na}$ análise qualitativa dos casos de deferimento pela autoridade competente da certificação de créditos de carbono a projetos florestais no Brasil (três casos), em dois deles fica patente o contrassenso da constituição de uma paradoxal figura de um atividade "poluidoracredora", incompatível com a principiologia jusambiental brasileira, se esta for corretamente interpretada.

5) O problema, porém, não parece estar no choque entre as normativas internacionais e nacionais, mas na necessidade de uma avaliação e interpretação mais cuidadosa por parte da autoridade nacional designada, com vistas a levar a sério uma adequada compreensão constitucional do desenvolvimento sustentável e da ilação destes com os princípios e regras do Direito ambiental brasileiro. 


\section{REFERÊNCIAS}

BARROSO, Luís Roberto. Interpretação e aplicação da constituição: fundamentos de uma dogmática constitucional transformadora. São Paulo: Saraiva. 1996.

BRASIL, Constituição (1988). Constituição da República Federativa do Brasil.

, Decreto $\mathrm{n}^{\mathrm{o}} 2.652$ de $1^{\circ}$ de Julho de 1998, que promulga a Convenção-Quadro das Nações Unidas sobre Mudança do Clima, assinada em Nova York, em 9 de maio de 1992.

, Decreto n. 7.390, de 09 de dezembro de 2010. Regulamenta os arts. 6o, 11 e 12 da Lei no 12.187, de 29 de dezembro de 2009, que institui a Política Nacional sobre Mudança do Clima - PNMC, e dá outras providências. Disponível em: <http://www.planalto.gov.br/ccivil_03/_ Ato2007-2010/2010/Decreto/D7390.htm>. Acessado em: 05 de novembro de 2015.

, Lei 9.605, de 12 de fevereiro de 1998. Dispõe sobre as sanções penais e administrativas derivadas de condutas e atividades lesivas ao meio ambiente, e dá outras providências. Disponível em: $<$ http://www.planalto. gov.br/CCIVIL_03/leis/L9605.htm>. Acessado em: 05 de novembro de 2015.

, Lei 12.187, de 29 de dezembro de 2009. Institui a Política Nacional sobre Mudança do Clima - PNMC e dá outras providências. Disponível em: $<$ http://www.planalto.gov.br/ccivil_03/_ato2007-2010/2009/lei/112187. $\mathrm{htm}>$. Acessado em: 05 de novembro de 2015.

, COMISSÃO INTERMINISTERIAL DE MUDANÇA GLOBAL DO CLIMA (Brasil). Relatório de atividades 2013-2014. 2015.

, Resolução $\mathrm{n}^{\circ} 2$, de 10 de agosto de 2005. Altera a Resolução $\mathrm{n}^{\circ} 1$ de 11 de setembro de 2003, que estabelece os procedimentos para aprovaçãodas atividades de projeto no âmbito do Mecanismo de Desenvolvimento Limpo do Protocolo de Quioto, aprova os procedimentos para as atividades de projetos de florestamento e reflorestamento no âmbito do Mecanismo de Desenvolvimento Limpo do Protocolo de Quioto e dá 
outras providências.

, Resolução $n^{\circ} 7$, de 05 de março de 2008. Altera as resoluções $n^{\circ} 1, n^{\circ} 2, n^{\circ} 3$ e $n^{\circ} 4$ desta mesma Comissão em relação aos convites de comentários enviados pelos proponentes do projeto aos agentes envolvidos, interessados e/ou afetados pelas atividades de projeto no âmbito do Mecanismo de Desenvolvimento Limpo e dá outras providências.

CANOTILHO, José Joaquim Gomes; LEITE, José Rubens Morato. Direito constitucional ambiental brasileiro. 6 ed. São Paulo: Saraiva. 2015.

CASARA,AnaCristina.Sustentabilidadenomecanismodedesenvolvimento limpo. 2007. Originalmente apresentada como dissertação de mestrado, Pontifícia Universidade Católica do Paraná, 2007.

HANUM, Danielle Fernandes Limiro. Mecanismo de desenvolvimento limpo: uma proposta para sustentabilidade do aterro sanitário de Goiânia. 2007. Originalmente apresentada como dissertação de mestrado, Universidade Católica de Goiás, 2007.

MACHADO, Diego Pereira. Direitos humanos. 3 ed. Salvador, Bahia: Editora Juspodivm. 2015.

MAZZUOLI, Valerio de Oliveira. Curso de Direito Internacional Público. 9. ed. São Paulo: Revista dos Tribunais. 2015.

MIALHE, Jorge Luís. Direito Ambiental como expressão dos Direitos Humanos: a relevância do direito à informação no Mercosul. In: Verba Juris, ano 5, n. 5, jan/dez, 2006, p. 207-227.

Organização das Nações Unidas [ONU], Convenção-quadro das nações unidas sobre mudança do clima, conferência das partes $n^{\circ}$ 03, Japão, 1997.

, Convenção-quadro das nações unidas sobre mudança do clima, conferência das partes n ${ }^{\circ}$ 07, decisão n 17, Marrocos, 2001.

, Convenção-quadro das nações unidas sobre mudança do clima, conferência das partes nº 20, decisão 1/CP.20, Peru, 2014.

, Convenção-quadro das nações unidas sobre mudança do clima, conferência das partes n ${ }^{\circ}$ 21, anexo da decisão 1/CP.21, França, 2015. 
, Secretaria de Mudança Climática das Nações Unidas, CDM methodology booklet. $7^{\text {a }}$ ed. Alemanha, 2015. p. 261-266. Disponível em: $<$ https://cdm.unfecc.int/methodologies/>. Acessado em: 07 de junho de 2016.

PINTO COELHO, Saulo de Oliveira. A sustentabilidade como princípio constitucional sistêmico e sua relevância na efetivação interdisciplinar da ordem constitucional econômica e social: para além do ambientalismo e do desenvolvimentismo. In: Revista da Faculdade de Direito de Uberlândia. Uberlândia. v 39, jan, 2011, p. 261-291.

, A sustentabilidade como um direito fundamental: a concretização da dignidade da pessoa humana e a necessidade de interdisciplinaridade do direito. In: Veredas do Direito. Belo Horizonte, v 8, n 15, jun, 2011, p. 9-24.

, Desarrollo humano crítico-inclusivo: crítica del derecho al desarrollo y desarrollo crítico del derecho. In: MOYANO DÍAZ, Yanko; PINTO COELHO, Saulo de Oliveira; MAYOS SOLSONA, Gonçal (Eds.). Postdisciplinariedad y desarrollo humano. entre pensamento y política. Barcelona: Linkgua. 2014. p. 41-63.

, Dignidade humana e interdisciplinaridade do direito ao desenvolvimento sustentável. In: Revista Bonijuris. Curitiba. v 24, n 7, jul, 2012, p. 22-28.

REALE, Miguel. Fontes e modelos do Direito: para um novo paradigma hermenêutico. São Paulo: Saraiva.1994.

RIBAS, LuizCésar; BRAUER, Antonieta Lima; BARBOSA, Ivo Francisco. Análise da política nacional sobre mudança climática em confronto com a política estadual sobre mudança climática no estado de São Paulo. In: 3rd International Workshop Advances in Cleaner Production, São Paulo, 2011 .

RORIZ, Giovana Ferro de Sousa. O sequestro florestal de carbono em áreas (re) florestadas como atividade agrária para um novo conceito de produtividade do imóvel agrário. 2010. Originalmente apresentada como dissertação de mestrado, Universidade Federal de Goiás, 2010. 
SABBAG, Bruno Kerlakian. Processo de incorporação da dimensão climática no ordenamento jurídico brasileiro e análise do caso do estado de São Paulo. 2013. Originalmente apresentada como dissertação de mestrado, Universidade de São Paulo, 2013.

SOUZA, André Luis Rocha de. Perfil do mercado de carbono no Brasil: análise comparativa entre os mercados regulado e voluntário. 2011. Originalmente apresentada como dissertação de mestrado, Universidade Federal da Bahia, 2011.

Recebido em: 29/12/2017.

Artigo aceito em: 09/05/2018.

\section{Como citar este artigo (ABNT):}

COELHO, Saulo de Oliviera Pinto; SILVA, Tiago Ducatti de Oliveira. CERTIFICAÇÃO DE CRÉDITO DE CARBONO NA SILVICULTURA DEESPÉCIES EXÓTICAS E O PARADOXO DO POLUIDOR-CREDOR. Veredas do Direito, Belo Horizonte, v. 15, n. 31, p. 325-350, jan./abr. 2018. Disponível em: $<$ http://www.domhelder.edu.br/revista/index.php/veredas/ article/view/1222>. Acesso em: dia mês. ano. 